\title{
Onycocaris longirostris Bruce, 1980 (Crustacea: Decapoda: Pontoniinae), new to the Australian fauna
}

\author{
A. J. BRUCE \\ Crustacea Section, Queensland Museum, P.O. Box 3300, South Brisbane, Queensland, Australia 4101.E-mail: abruce@broad.net.au
}

\begin{abstract}
A heterosexual pair of specimens of Onycocaris longirostris Bruce, 1980, previously known only from the single incomplete male holotype from New Caledonia, are reported from the Kimberley region of Western Australia. With the male major second pereiopod and both female second pereiopods, these intact specimens enable the description of the species to be completed. A new record for Australian waters, it increases to 8 the number of Onycocaris species known from Australia.
\end{abstract}

Key words: Crustacea, Decapoda, Pontoniinae, Onycocaris longirostris Bruce, 1980, second record, Kimberley region, Western Australia, Callyspongia host, description of second pereiopod chelae

\section{Introduction}

The heterosexual pair of specimens collected during the Western Australian Museum 2011 Kimberley Survey, sponsored by Woodside Energy, are identified as Onycocaris longirostris Bruce, 1980, previously known only by the male holotype specimen from Nouméa, New Caledonia. This specimen was incomplete, with only a single second pereiopod, which was considered to be the minor appendage. The Kimberley specimens fortunately both have the second pereiopods attached and these are now described and illustrated, completing the description of the species. The life colouration is described for the first time and a new host record is added. The specimens are deposited in the collections of the Western Australian Museum, Perth.

Abbreviations used: CL, post-orbital carapace length; WAM, Western Australian Museum, Perth.

\section{Systematics}

Family Palaemonidae Rafinesque, 1815

Subfamily Pontoniinae Kingsley, 1879

Genus Onycocaris Nobili, 1904

Onycocaris longirostris Bruce, 1980 (Figs 1-4)

Onycocaris longirostris Bruce, 1980, Cahiers Indo-Pacifique, 2(1): 15-25, figs. 6-10.

Material examined.. 1 $\widehat{\jmath}, 1$ ovig. $\odot$, Western Australia, Woodside Kimberley Survey 2011, stn 89/K11, Irvine and Bathurst Islands, intertidal, mid-littoral reef platform, $16^{\circ} 3^{\prime} 19^{\prime \prime} \mathrm{S} 123^{\circ} 32^{\prime} 47^{\prime \prime E}$, coll. A. Hosie, 25 October 2011, WAM C48779.

Diagnosis. A large Onycocaris species with well developed rostrum extending to distal end of antennular peduncle, dorsally carinate with 2-3 acute teeth on distal half; second pereiopods unequal in male, slightly 
dissimilar, with distolateral flange on minor chela only, and subequal, similar in female, both sexes with large acute preterminal distolateral tooth on merus.

\section{Description.}

Male. Agreeing closely with the original description, with two dorsal rostral teeth, with both second pereiopods preserved.

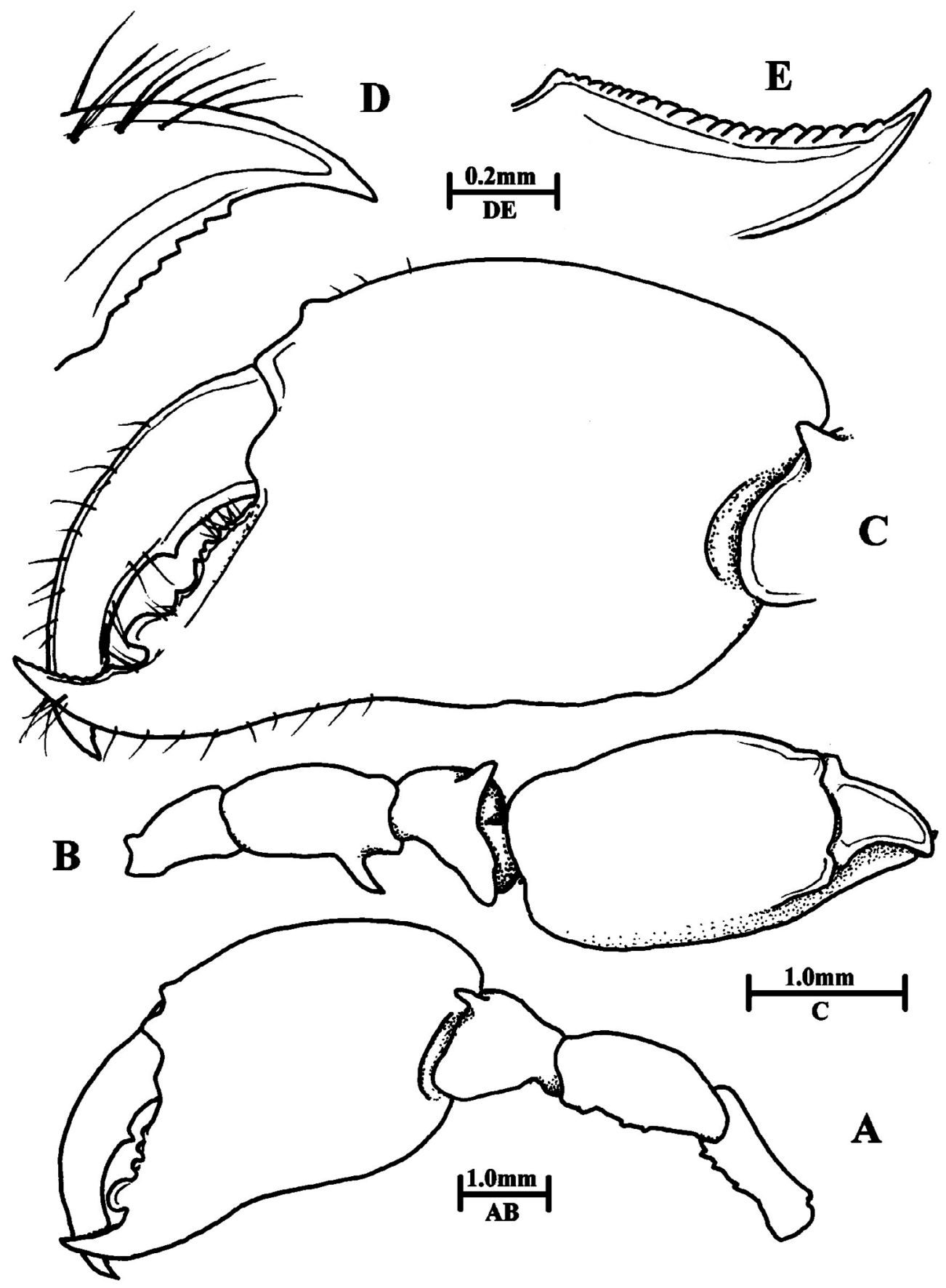

FIGURE 1. Onycocaris longirostris Bruce, 1980, male, Irvine and Bathurst Islands, WAM C48779. A, major second pereiopod, medial. B, same, dorsal. C, chela. D, dactylus, tip. E, fixed finger, tip.

Major second pereiopod (right) (Fig. 1AB) with chela (Fig. 1C) about 2.5 times CL, palm smooth, swollen, about 1.25 times longer than deep, flattened medially, convex laterally, sparsely setose, fingers about 0.6 of palm length, dactyl slender, curved, medially concave, about 3.5 times longer than proximal depth, cutting edge biconcave, proximal major portion with single small acute tooth at half length, distal portion (Fig. 1D) with six 
small subacute teeth, extending onto stout tip, fixed finger robust, medially concave, about 1.25 times longer than proximal depth, with stout acute tip, cutting edge complex, with stout bluntly subquadrate tooth, feebly anteroverted, at about 0.6 of length, with small acute tooth and series of four rounded teeth, distally with series of 20 stout rounded teeth (Fig. 1E) extending to near tip, separated by deep smooth notch from subquadrate tooth, without lateral flange; carpus robust about 0.33 of palm length, tapering proximally, distally excavate, with blunt distodorsal tooth medially, merus robust, about 0.5 of palm length, slightly swollen centrally, 2.0 times longer than central width, with 2 mall acute tubercles ventrally, large acute preterminal tooth distolaterally; ischium $0.5 \mathrm{of}$ palm length, 0.95 of merus length, 3.4 times longer than distal width, tapering proximally, with 3 acute ventral tubercles; basis and coxa robust, without special features.

Minor second pereiopod (left) (Fig. 2A) generally similar to major pereiopod, with chela about 1.25 times CL, 0.73 of major chela length; finger (Fig. 2B) similar to major chela, dactylus (Fig. 2C) slender, concave medially, with groups of long setae along upper medial margin, cutting edge with small acute tooth at half length and four smaller rounded teeth proximally, distally unarmed proximally, with nine stout acute teeth distally, extending to near tip; fixed finger with blunt tooth at about half length, proximal margin with small acute tooth, separated by small gap from four small rounded teeth, largest distally, decreasing in size proximally, distally with small gap separating from row of 12 large blunt teeth extending almost to tip, with small rounded preterminal accessory flange distolaterally, dorsal margin with about 13 small rounded teeth, decreasing in size proximally and distally, distal dactylus opposing into groove medial to flange; proximal segments similar to major chela but smaller and slimmer.

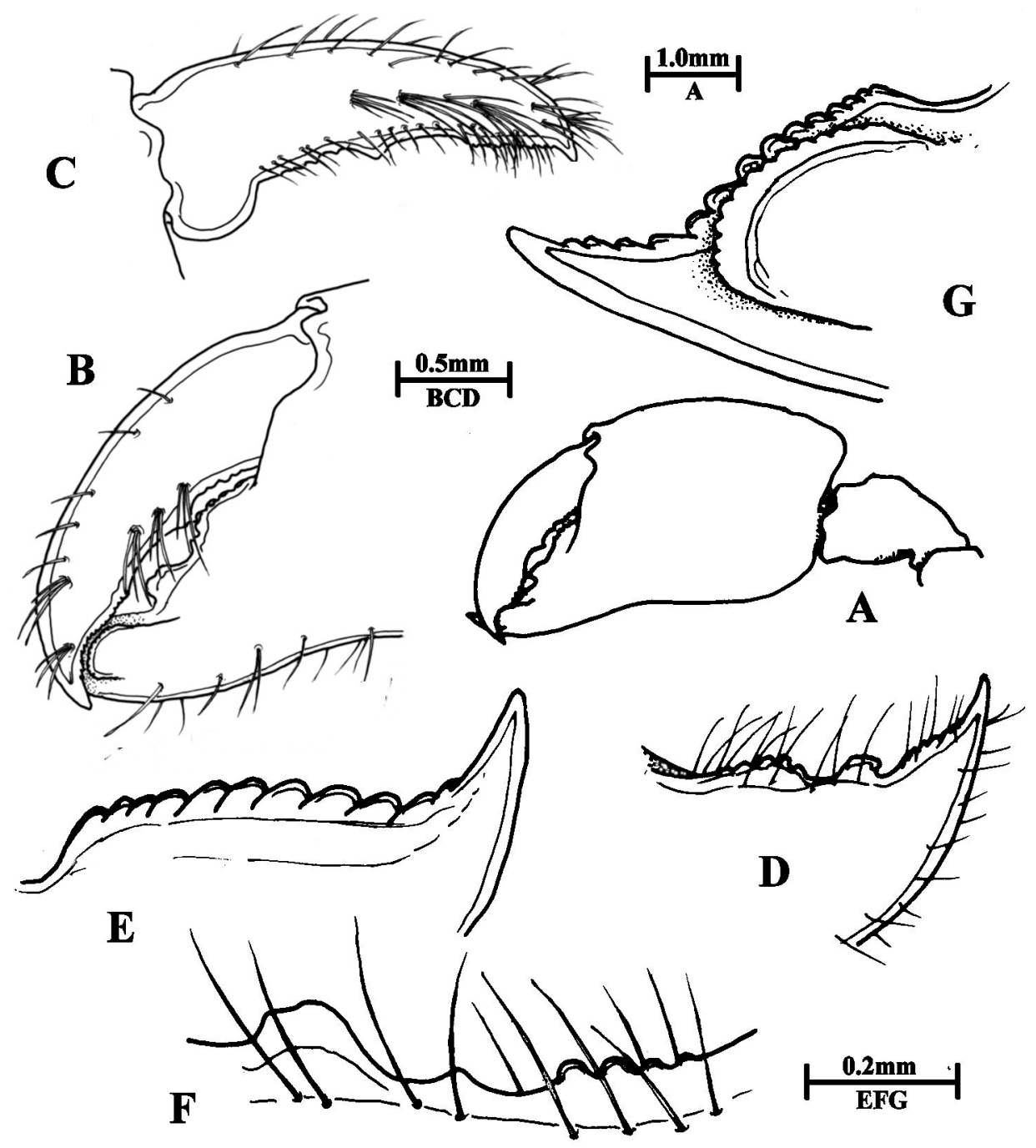

FIGURE 2. Onycocaris longirostris Bruce, 1980, male, Irvine and Bathurst Islands, WAM C48779. Minor second pereiopod. A, chela, lateral. B, same, fingers. C, same, dactylus, medial. D, same, distal fixed finger. E, same, distal fixed finger. F, same, proximal fixed finger. $\mathrm{G}$, same, ventrolateral. 
Female. Generally similar to the male but considerably larger, rostrum about 0.18 of CL, with three dorsal rostral teeth, with relatively smaller subequal, similar second pereiopods, with very numerous ova.

Second pereiopod chela (right) (Fig. 3A) about 1.09 times CL, palm 1.14 times longer than deep, slightly compressed, medial side flattened, lateral side rounded, smooth, sparsely setose; dactylus (Fig.3BC) slender, tapering distally to small hooked tip, about 0.9 of palm length, 4.0 times longer than central depth, medially scaphoid, cutting edge (Fig.3D) complex, with truncate tooth at about half length, distal third with irregular series of blunt teeth extending to near short acute slightly hooked tip, proximal cutting edge concave, proximally swollen, with four small irregular teeth; fixed finger (Fig. 3BC) about 1.4 times longer than proximal depth, with stout acute tip, cutting edge with truncate tooth at half length, distal cutting edge (Fig.3E) with series of teeth, rounded proximally, acute distally, extending to near tip, proximal cutting edge (Fig. 3F) with series of crenulate teeth, about twelve, largest centrally, distolateral surface with rounded laminar flange (Fig.3G); proximal segments similar to holotype. Left second pereiopod similar to right.

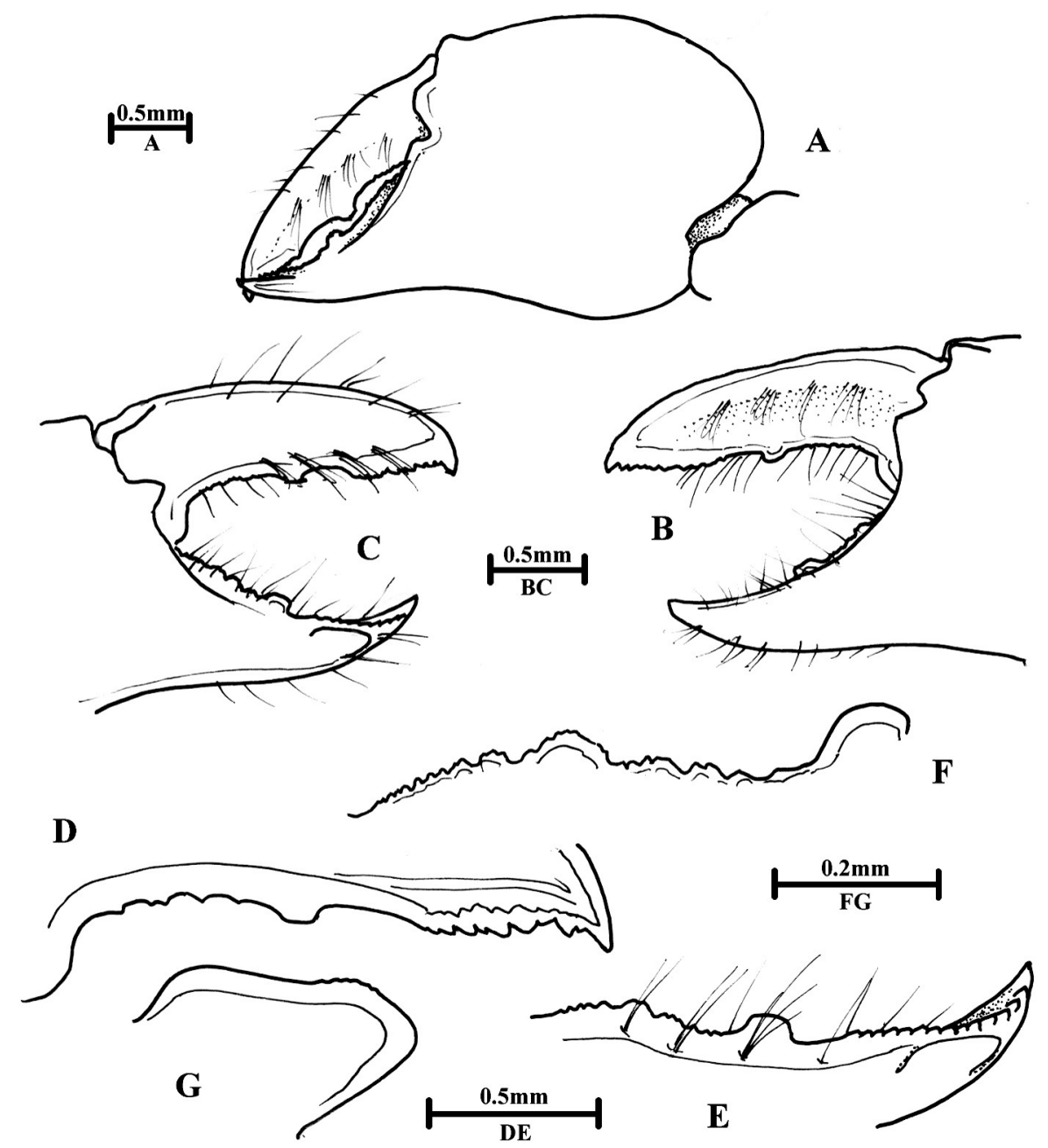

FIGURE 3. Onycocaris longirostris Bruce, 1980, female, Irvine and Bathurst Islands, WAM C48779. A, right second pereiopod chela, medial aspect. B, same, fingers, medial. C, same, lateral. D, dactyl, cutting edge, lateral. E, fixed finger, cutting edge, lateral. F, same, proximal cutting edge. G, fixed finger, distolateral flange.

Measurements. Male, CL 3.2mm; CL and rostrum, 5.6mm; total body length (approx.) $12.6 \mathrm{~mm}$; major second pereiopod chela, $6.0 \mathrm{~mm}$; minor second pereiopod chela $4.4 \mathrm{~mm}$. Female, CL 4.1; CL and rostrum, 4.7; total body length (approx.) 15.5; second pereiopod chelae, $4.3 \mathrm{~mm}$; length of ovum, $0.5 \mathrm{~mm}$.

Colouration (from photo). Body and appendages translucent whitish, carapace and abdomen with scattered small white chromatophores, hepatopancreas pale olive green (Fig. 4).

Host. Callyspongia sp. [Porifera], a new host record, the holotype having been found in association with Siphonochalina sp. (Bruce, 1980).

Associated fauna. Periclimenaeus rastrifer Bruce, 1980, one male, WAM C48918. 


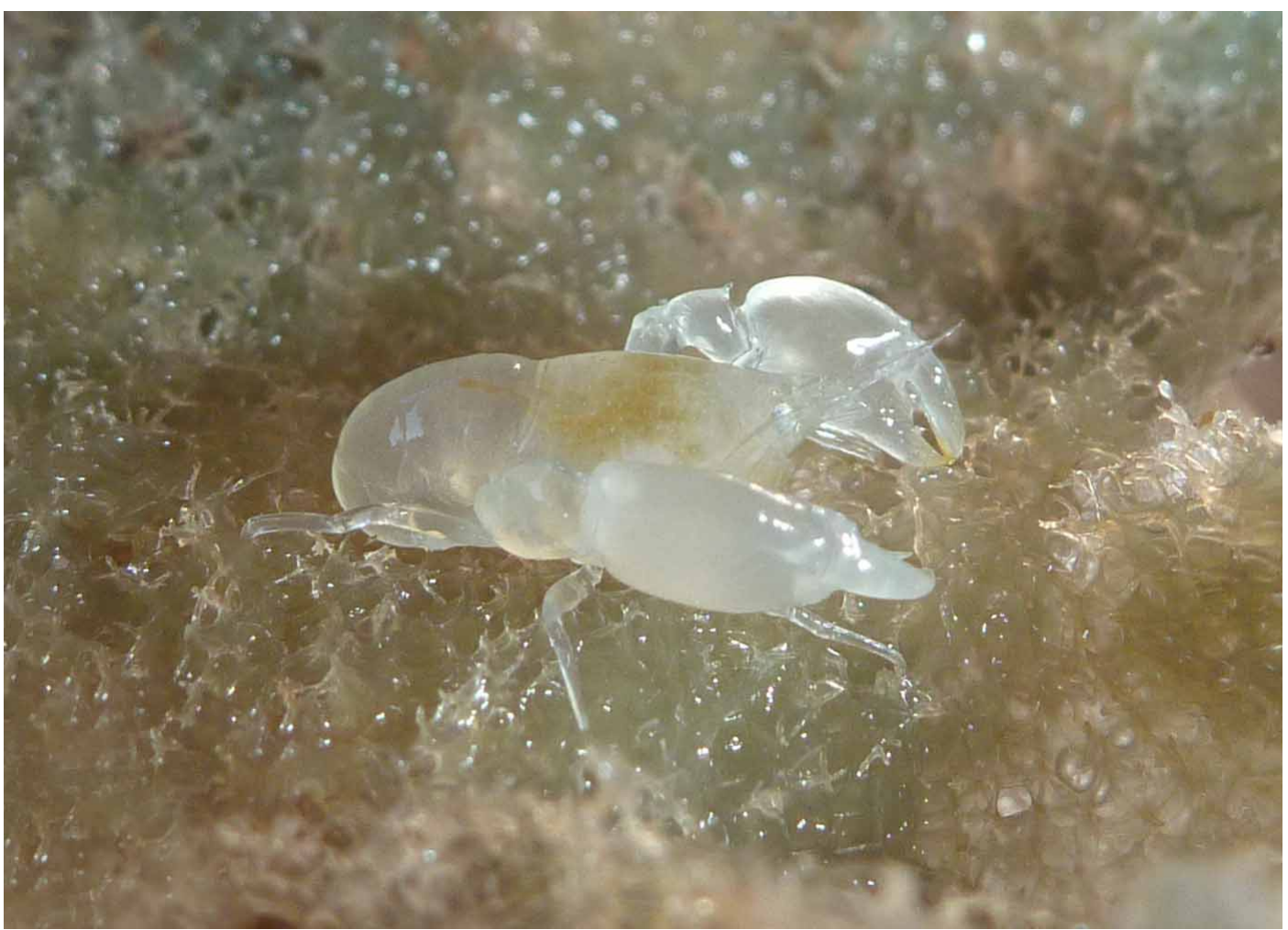

FIGURE 4. Onycocaris longirostris Bruce, 1980, male, Irvine and Bathurst Islands, WAM C48779, photo by Andrew Hosie.

Remarks. With the inclusion of Onycocaris longirostris, eight of the 18 known species of the genus are now known from Australian waters: from Western Australia, Onycocaris quadratophthalma (Balss, 1921) and $O$. longirostris Bruce, 1980; from the Northern Territory, O. balssi Bruce, 2011; from Queensland, O. amakusensis Fujino \& Miyake, 1969; O. nieli Bruce, 2011 O. oligodentata Fujino \& Miyake, 1969; O. spinosa Fujino \& Miyake, 1969 and O. stradbrokei Bruce, 1998. Keys for the identification of these species can be found in Bruce (2011).

The original description of $O$. longirostris was based on a single male specimen which lacked one of the second pereiopods. The preserved second pereiopod was considered to be the minor appendage and this is now confirmed. The present male specimen also indicates that the second pereiopod chelae are distinctly unequal and slightly dissimilar as the major chela lacks the well developed small distolateral accessory flange present on the fixed finger of the minor chela. In contrast, the female has subequal and similar second pereiopods, very similar to the male minor second pereiopod chela, with an unarmed distolateral laminar flange.

\section{Acknowledgements}

I am most grateful to Andrew Hosie for the opportunity to report on these specimens and the use of his photo. The Western Australian Museum Kimberley 3011 expedition was funded by Woodside Energy. This study was supported by the Australian Biological Resources Study.

\section{References}

Bruce, A.J. (1980) On some pontoniine shrimps from Nouméa, New Caledonia. Cahiers de l'Indo-Pacifique, 2(1), 1-9, figs 114.

Bruce, A.J. (2011) Notes on some Indo-Pacific Pontoniinae, XLVIII. Onycocaris nieli sp. nov., a new pontoniine shrimp from Heron Island, Queensland, Crustaceana, 84(3), 319-330, figs 1-5. 